\title{
A Study to Assess the Knowledge Regarding Health Hazards of Plastic in Domestic Use and Attitude toward the use of Alternatives in Women Residing at Mohan Kumar Nagar, Bengaluru
}

\author{
B. Geetha Praveena \\ Department of Community Health Nursing, GSL College of Nursing, Rajahmundry, Andhra Pradesh, India
}

\section{Abstract}

Background: Plastic bag users are at risk of number of health hazards. There is a paucity of data with regard to awareness of health hazards among the general population in India.

Aim: A study was to assess the knowledge regarding health hazards of plastic in domestic use and attitude toward the use of alternatives in women residing at Mohan Kumar (MK) Nagar, Bengaluru.

Methodology: Non-experimental descriptive design was adopted in the present study. Simple random sampling technique was used to select the sample size of 100 women residing in the MK Nagar, Bengaluru. Tool consisted of a structured knowledge questionnaire and attitude questionnaire regarding health hazards of plastic in domestic use and attitude toward the use of alternatives.

Results: About 55\% had inadequate knowledge, $45 \%$ had moderately adequate knowledge, and none of them had adequate knowledge. Regarding the quality of attitude, $24 \%$ had negative attitude, $73 \%$ had neutral attitude, and $3 \%$ had positive attitude toward the use of alternatives.

Conclusion: The community health nurse must constantly focus her effort on improving the knowledge of women regarding health hazards of plastic in domestic use through health education, mass media, teaching program, etc.

Keywords: Health hazards, nursing, plastic bag

\section{INTRODUCTION}

Plastic industry is one among the rapidly growing industries in India. The production of plastics has reached 8.5 million tons in 2013 with a growth rate of $8 \%$ over the previous 5 years. The growth rate is expected to be $10 \%$ over the next 5 years. ${ }^{[1]}$ The reasons for popularity for using the plastic bags are lightweight, resistance to degradation (by chemicals, sunlight, and bacteria), durability, and above all low cost.

Access this article online

Website: http://innovationalpublishers.com/Journal/ijnmi

ISSN No: $2656-4656$

DOI: $10.31690 / \mathrm{ijnmi} / 50$
While these conveniences are benefitting individual users, the problems and the cost of disposal of plastic items would burden the entire society. ${ }^{[2]}$ After their entry to environment, plastics take anywhere from 15 to 1000 years to biodegrade. ${ }^{[3]}$ It poses a risk to human health and environment. ${ }^{[4]}$ In addition to problems such as choking the drains, the littered plastic bags are breeding ground for mosquitoes when rainwater gets collected in them. This could worsen the situation of malaria in a highly endemic area.

Plastic bag packing for hot edible items causes migration of harmful chemicals to food items. These include styrene which is carcinogenic, phthalates, and bisphenol which causes diabetes and diseases of the heart and liver. ${ }^{[5]}$ Therefore, it is high time we switch over to alternative materials for packing and transportation. 
“The Plastics Manufacture, Sale and Usage Rules 1999, amended in 2003 under the Indian environment (protection) act of 1986 prohibit manufacture, stocking, distribution, or sale of carry bags made of virgin or recycled plastic and prohibits littering of plastic items."[2]

Keeping all these above facts in mind, the investigator personal interest encourages the investigator to select the topic to assess the knowledge of women regarding health hazards of plastic in domestic use and as the people may have the knowledge they can be able to prevent the health hazards by developing the positive attitude toward the use of alternatives. The study was aimed to assess the knowledge regarding health hazards of plastic in domestic use and attitude toward the use of alternatives in women residing at Mohan Kumar (MK) Nagar, Bengaluru.

\section{Subjects and Methods}

This non-experimental study was conducted at Mohan Kumar Nagar, Bengaluru. The criteria for selecting this setting were geographical proximity, feasibility of conducting study, availability of samples, and familiarity of the investigator with the setting. The study population consisted of 100 women. Women were included if they were in the age group of 20-60 years, residing at MK Nagar, willing to participate in the study, and availability during the period of data collection. Women were excluded if they were not able to read, understand, and respond in English or Kannada and not willing to participate.

\section{Tool}

The tools consisted of structured questionnaire and a 5-point rating Likert scale. The description of tools is as follows:

\section{Structured questionnaire}

It consisted of two sections. Section A consisted of 7 items related to sociodemographic profile. Section B consisted of 25 items including general information of plastic use (10 questions), health hazards of plastic (10 questions), disposal of plastic (3 questions), and alternative to plastics (2 questions). The score was categorized into three groups on the basis of scores with adequate knowledge $(>75 \%)$, moderately adequate knowledge (51-75\%), and inadequate knowledge ( $\leq 50 \%)$.

\section{Likert scale}

The attitude scale consists of 5-point rating scale, in which there are five options for 14 positive questions. A score of 5 was awarded for strongly agree, 4 was awarded for agree, 3 for neutral, 2 for disagree, and 1 for strongly disagree and for the six negative questions, a score of 5 was awarded for strongly disagree, 4 was awarded for disagree, 3 for neutral, 2 for agree, and 1 for strongly agree; thus, a total of 100 marks are allotted to interpret the score it was categorized into negative attitude $(\leq 50 \%)$, neutral attitude $(51-75 \%)$, and positive attitude $(>75 \%)$.

\section{Content validity}

Content validity of the tool was established by nine experts, comprising seven nursing experts from community health nursing department, one primary health care medical officer, and two professors of the department of community health. Minor suggestions regarding rearranging of questions, difficult words were converted into simple words. The final tool was prepared as per the suggestions and advice given by the experts.

\section{Reliability}

The reliability of the tool was obtained by split-half method. The reliability score obtained was $r=0.78$ for knowledge and $r=0.81$ for attitude, respectively.

\section{RESULTS}

Table 1 shows the frequency and percentage distribution of women with respect to age, majority of the subjects $66(66 \%)$ belongs to the age group between 21 and 30 years and $15(15 \%)$ of the subjects belongs to the age group of 31-40 years and $19(19 \%)$ of the subjects belongs to the age group of 41-50 years. On considering the educational status, majority of the subjects $47(47 \%)$ had primary education, $12(12 \%)$ had non-formal education, $34(34 \%)$ had secondary education, and only 7 (7\%) of them had graduation. On considering the occupation, majority of the subjects $65(65 \%)$ were housewife's and $16(16 \%)$ of the subjects private employee and only $4(4 \%)$ of the subjects were government employee and $15(15 \%)$ of the subjects were doing their own business. With regard to the

Table 1: Frequency and percentage distribution of sociodemographic variables of women according to their age, educational status, occupation, and type of family

\begin{tabular}{|c|c|c|}
\hline Sociodemographic variables & Frequency & Percentage \\
\hline \multicolumn{3}{|l|}{ Age in years } \\
\hline $21-30$ & 66 & 66 \\
\hline $31-40$ & 15 & 15 \\
\hline $41-50$ & 19 & 19 \\
\hline $51-60$ & - & - \\
\hline \multicolumn{3}{|l|}{ Educational status } \\
\hline Non-formal education & 12 & 12 \\
\hline Primary education & 47 & 47 \\
\hline Secondary education & 34 & 34 \\
\hline Graduation & 7 & 7 \\
\hline Others & - & - \\
\hline \multicolumn{3}{|l|}{ Occupation } \\
\hline Housewife & 65 & 65 \\
\hline Private employee & 16 & 16 \\
\hline Government employee & 4 & 4 \\
\hline Business & 15 & 15 \\
\hline Others & - & - \\
\hline \multicolumn{3}{|l|}{ Type of family } \\
\hline Nuclear & 60 & 60 \\
\hline Joint & 40 & 40 \\
\hline \multicolumn{3}{|l|}{ Family income (Rs/month) } \\
\hline$<2500$ & 29 & 29 \\
\hline $2500-3000$ & 26 & 26 \\
\hline $3000-3500$ & 7 & 7 \\
\hline $3500-4000$ & 13 & 13 \\
\hline$>4000$ & 25 & 25 \\
\hline \multicolumn{3}{|l|}{ Use of plastic } \\
\hline Yes & 100 & 100 \\
\hline No & - & - \\
\hline \multicolumn{3}{|l|}{ Type of use } \\
\hline Storage of food items & 29 & 29 \\
\hline Multipurpose & 71 & 71 \\
\hline
\end{tabular}


Table 2: Frequency and percentage distribution of the level of knowledge regarding health hazards of plastic in domestic use in women

\begin{tabular}{|c|c|c|c|c|c|c|}
\hline \multirow[t]{2}{*}{ Areas } & \multicolumn{2}{|c|}{ Inadequate $\leq 50 \%$} & \multicolumn{2}{|c|}{ Moderately adequate $51-75 \%$} & \multicolumn{2}{|c|}{ Adequate $>75 \%$} \\
\hline & Frequency & Percentage & Frequency & Percentage & Frequency & Percentage \\
\hline General information & 30 & 30 & 70 & 70 & 0 & 0 \\
\hline Health hazards of plastic & 33 & 33 & 63 & 63 & 4 & 4 \\
\hline Disposable of plastic & 74 & 74 & 26 & 26 & 0 & 0 \\
\hline Alternatives to plastic & 42 & 42 & 43 & 43 & 15 & 15 \\
\hline Overall & 55 & 55 & 45 & 45 & 0 & 0 \\
\hline
\end{tabular}

Table 3: Frequency and percentage distribution of quality of attitude toward the use of alternatives in women

\begin{tabular}{|c|c|c|c|c|c|c|}
\hline \multirow[t]{2}{*}{ Variable } & \multicolumn{2}{|c|}{ Negative attitude $\leq \mathbf{5 0} \%$} & \multicolumn{2}{|c|}{ Neutral attitude $51-75 \%$} & \multicolumn{2}{|c|}{ Positive attitude $>75 \%$} \\
\hline & Frequency & Percentage & Frequency & Percentage & Frequency & Percentage \\
\hline Attitude & 26 & 26 & 71 & 71 & 3 & 3 \\
\hline
\end{tabular}

type of family, the majority of subjects $60(60 \%)$ belongs to nuclear family and only 40 (40\%) of them belong to joint family. Twenty-nine (29\%) of them were earning below Rs. 2500 and $26(26 \%)$ of the subjects were earning between Rs. 2500 and 3000 and 7 (7\%) of the subjects were earning between Rs. 3000 and 3500 and $13(13 \%)$ of the subjects were earning between 3500 and 4000 and 25 (25\%) of the subjects were earning above Rs. 4000. On considering the use of plastic, 100 (100\%) of the subjects were using plastic. With regard to the type of use, majority of the subjects 71 (71\%) were using it for multipurpose and $29(29 \%)$ of them were using for storage of food items.

\section{Knowledge regarding health hazard}

Table 2 shows that on considering the general information regarding plastic in domestic use, $30(30 \%)$ of the subjects had inadequate knowledge, $70(70 \%)$ of the subjects had moderately adequate knowledge, and none of them had adequate knowledge. On considering the health hazards of plastic, $33(33 \%)$ of the subjects had inadequate knowledge, $63(63 \%)$ of the subjects had moderately adequate knowledge, and 4 (4\%) of the subjects had adequate knowledge. Regarding the disposable of plastic, $74(74 \%)$ of the subjects had inadequate of knowledge and $26(26 \%)$ of the subjects had moderately adequate knowledge and none of them had adequate knowledge. With regard to the use of alternatives to plastic, $42(42 \%)$ of the subjects had inadequate knowledge, 43 (43\%) of the subjects had moderately adequate knowledge, and $15(15 \%)$ of the subjects had adequate knowledge. Overall, 55 (55\%) of the subjects had inadequate knowledge, 45 (45\%) of subjects had moderately adequate knowledge, and none of them had adequate knowledge.

\section{Attitude toward the use of alternatives of plastics}

Table 3 revealed that majority of the subjects $71(71 \%)$ had neutral attitude and $26(26 \%)$ of the subjects had negative attitude, whereas only $3(3 \%)$ of the subjects had positive attitude toward the use of alternatives.

\section{Discussion}

Most of the women in our study have moderate knowledge of health hazards of plastic use. This was better than the observations found in studies conducted in India and other parts of the world where $50-81.1 \%$ of participants were aware of associated health hazards. ${ }^{[3,5]}$

In a Delhi-based study, $74.5 \%$ of housewives and $81.5 \%$ of professionals were aware of health hazards associated with the usage of plastics and it was lower than our observations. ${ }^{[6]}$ However, the awareness among students (93\%) and lowerincome groups (52\%) in the Delhi-based study was more than our observations. Awareness of students is very vital for any awareness campaign. Students by means of their academic curriculum are expected to be knowledgeable on various public health issues concerning the society which includes hazards of plastic bag use. They can, hence, play a productive role in health education activities in the community. This would help the government and non-government organizations by avoiding extra financial burden to train the additional personnel. Poor awareness among people, in general, has been reported as the leading cause in developing countries resulting in adopting environmentally unfriendly practices. ${ }^{[2]}$

The various means to enable easy availability of information should support awareness generation initiatives. For example, display of banners with the intention of creating awareness of the use of alternative bags could be an effective low-cost information strategy. Pamphlets on hazards of plastic bags need to be put up near checkouts or cash counters in grocery stores and shops. Radio and television can also help in mass dissemination of information. This will motivate both adults and children to use alternate eco-friendly bags such as paper or cloth bags. ${ }^{[3,6]}$ The most common reasons for preferring plastic bags found in this study were the easy availability followed by durability. This was similar to the findings of the study done in Delhi where convenience for shopping was the most common reason stated by most participants. ${ }^{[6]}$ Another study done in an urban area of Ethiopia reported that low price, easy availability, and lightweight were the main reasons for popularity of plastic bags among its users. ${ }^{[7]}$

\section{Conclusion}

The study concluded that the level of knowledge regarding health hazards of plastic in domestic use; it was found that 
$55 \%$ had inadequate knowledge, $45 \%$ had moderately adequate knowledge, and none of them had adequate knowledge. Regarding quality of attitude, 24\% had negative attitude, $73 \%$ had neutral attitude, and $3 \%$ had positive attitude toward the use of alternatives.

\section{RefERENCES}

1. Federation of Indian Chambers of Commerce and Industry. A Report on Plastics Industry. New Delhi: TATA Strategic Management Group; 2014. Available from: http://www.ficci.com/spdocument/20396/ Knowledge-Paper-ps.pdf. [Last accessed on 2019 Aug 29].

2. Gupta K, Somanathan R. Consumer Response to Incentives to Reduce Plastic Bag Use: Evidence from a Field Experiment in Urban India. Delhi: Delhi School of Economics; 2011. Available from: http://www. isid.ac.in/ pu/conference/dec_11_conf/Papers/KanupriyaGupta.pdf. [Last accessed on 2019 Aug 29].

3. Sutton J, Turner B. Plastic Bags: Hazards and Mitigation. California: Social Sciences Department, California Polytechnic State University;
2012. Available from: http://www.digitalcommons.calpoly.edu/cgi/ viewcontent.cgi?article $=1082 \&$ context $=$ socssp. . Last accessed on 2019 Sep 01].

4. Halden RU. Plastics and health risks. Ann Rev Public Health 2010;31:179-94.

5. Sung GB. Ban on Plastic Bags Usage: Is it a Right Move? An Empirical Study on Consumer Perception and Practice. Gelugor: Universiti Sains Malaysia; 2010.

6. Abhigyan. Use of Plastic Bags: Factors Affecting Ecologically Oriented Behavior in Consumers. Delhi: Foundation for Organisational Research and Education; 2008. Available from: http://www.freepatentsonline.com/ article/Abhigyan/192438179.html. [Last accessed on 2019 Sep 01].

7. Adane L, Muleta D. Survey on the usage of plastic bags, their disposal and adverse impacts on environment: A case study in Jimma city, Southwestern Ethiopia. J Toxicol Environ Health Sci 2011;3:234-48.

How to cite this article: Praveena BG. A Study to Assess the Knowledge Regarding Health Hazards of Plastic in Domestic Use and Attitude toward the Use of Alternatives in Women Residing at Mohan Kumar Nagar, Bengaluru. Int J Nurs Med Invest. 2019;4(3):50-53 